\title{
Modifying the Attitudes of Nonhandicapped High School Students Toward Handicapped Peers
}

\author{
CRAIG R. FIEDLER \\ RICHARD L. SIMPSON
}

\begin{abstract}
Two curricular approaches for modifying nonhandicapped high school students' attitudes toward their exceptional peers were compared. One curriculum was structured around categories of exceptionality (e.g., mental retardation, sensory impairments) while the other focused on generic concepts, including values, conformity, individual differences, and labeling effects. Each curriculum was presented over a 10-week period and the effects assessed via two pencil-paper attitude evaluation scales. Results revealed that both curricula positively modified students' attitudes, with subjects exposed to the categorical curriculum demonstrating significantly greater attitude changes. The data are interpreted relative to the issue of labeling and the most effective means of positively modifying attitudes toward handicapped persons.
\end{abstract}

As a result of recent litigation, legislation, and the efforts of parent and professional advocates, the trend to integrate handicapped individuals into the mainstream of society has increased dramatically (Novak \& Heal, 1980). The philosophical fuel igniting this community integration movement is embodied in the normalization principle, which stresses service in environments and under circumstances that are as culturally normal as possible (Nirje, 1969; Wolfensberger, 1972). Acceptance of normalization and hence the integration mandate presup-

CRAIG R. FIEDLER is Assistant Professor, Department of Education, University of New Hampshire, Durham. RICHARD L. SIMPSON is Professor, Department of Special Education, University of Kansas, Lawrence. poses a personal attitude that affirms the developmental potential and rights of all human beings, regardless of type and severity of disability (Wolfensberger, 1972). Thus, to a great extent, successful integration relies on systematic encouragement of positive attitudes toward handicapped individuals. Fostering postitive attitudes toward handicapped people is increasingly being viewed as a responsibility of the public schools (McHale \& Simeonsson, 1980; Simpson, 1980; Voeltz, 1980, 1982). Indeed, as cautioned by Martin (1974), unless educators develop strategies for creating an attitude of acceptance in students in regular education toward their handicapped peers, "we will be painfully naive, and I fear we will subject many children to a painful and frustrating educational experience in the name of progress"' ( $p$. 150). 


\section{ATTITUDE-CHANGE CURRICULA}

The existence of negative and stereotypic attitudes toward handicapped individuals is well documented (Ayer, 1970; Barker, Wright, Meyerson, \& Gonich, 1953; Larsen, 1975; Panda \& Bartel, 1972; Yuker, Block, \& Young, 1970). School-based attempts at modifying such attitudes have fallen into two general categories: (a) efforts aimed at attitude change through increased exposure to and contact with handicapped individuals; and (b) curricular interventions (informational presentations about handicapped individuals) (Evans, 1976; Stainback, Stainback, Raschke, \& Anderson, 1981). This latter approach is particularly well suited for regular educators in their efforts to foster positive attitudes toward handicapped persons.

Most of the existing attitude-change curricula (Barnes, Berrigan, \& Biklen, 1978; Biklen \& Sokoloff, 1978; Bookbinder, 1978; Cohen, 1977; Newman \& Simpson, 1983; Reinhardtsen, 1980) have been efficacious in positively modifying nonhandicapped students' attitudes. The common element in these curricula is the presentation of information about conceptually ordered categorical disability labels (e.g., mentally retarded, emotionally disturbed, learning disabled), based on the assumption that the use of labels effectively conveys information about handicapped individuals. This assumption does not, however, give adequate consideration to the potential adverse effects of labels on nonhandicapped persons' perceptions and, ultimately, their treatment of handicapped individuals.

\section{EFFECTS OF CATEGORICAL LABELING}

For a number of years, investigators in the fields of education and psychology have reached conflicting conclusions about the effects of labeling handicapped individuals. Several investigators have reported no negative effects from this practice. Simpson (1980), for example, suggested that "attitudes toward handicapped children and youth may exist whether or not the exceptional pupils have been formally 'labeled' and assigned to a special education program" (p. 3). MacMillan, Jones, and Aloia (1974) found no conclusive evidence of the negative effects of the label "mentally retarded." In fact, some researchers have argued that concern over the effects of labeling is misplaced
(Wilson, 1970). Further, Guskin (1963) cited evidence indicating that labeling may increase peer acceptance of retarded children by making their behavior more acceptable. That is, by reducing the discrepancy between expected and actual behavior, a label may cause nonhandicapped individuals to use a different standard by which to judge handicapped persons.

In spite of such potentially positive effects, the use of labels as referents in the study of handicapped people is still surrounded by controversy (Fiedler, 1978; Foster, Ysseldyke, \& Reese, 1975; Ramsey, 1978). Some investigators maintain that labels have serious detrimental effects on handicapped individuals. For example, Bogdan and Taylor (1982) believe that labels create barriers to understanding handicapped individuals by encouraging nonhandicapped people to define them in terms of a single dimension, which, in turn, is used to generalize about the labeled person's character and ability.

The unquestioned adherence to a categorically based curriculum in most attitudemodification efforts has resulted in a lack of intervention alternatives. Furthermore, the effectiveness of noncategorical informational presentations has not been investigated. Such a curriculum would not structure information according to categorical labels, but around social, ecological, and psychological issues related to the integration of handicapped persons. Presumably, the potentially pernicious effects of labeling would be absent from a noncategorical curriculum.

\section{PURPOSE}

In an effort to address the labeling issue, the present study was designed to investigate the effects of two types of structured informational curricula (categorical and noncategorical) in positively modifying nonhandicapped high school students' attitudes toward handicapped people. Categorical curricula have proven effective in disseminating information of a cognitive nature-definitions, causes, and characteristics of disabling conditions. However, the categorical use of labels and the possible creation of stereotypical images leave unanswered serious questions concerning their potentially detrimental effects on nonhandicapped students' feelings and attitudes toward handicapped persons. Hence the interest in a noncategorical 
approach to information dissemination and attitude-change programs for nonhandicapped individuals.

\section{METHOD}

\section{Subjects and Setting}

A total of 90 subjects participated in this study ( $48 \%$ were males, and $52 \%$ were females). Subjects were randomly selected from six 11thgrade social studies classrooms $(N=15$ per classroom). Social studies was a required course for all 11th-grade regular education students in the sample population. Honors students were not included, nor were any academically (or otherwise) handicapped students chosen as subjects. Four classes, all students of the same teacher, served as the treatment groups. These adolescents were exposed to either a categorical or a noncategorical curriculum designed to positively modify attitudes toward handicapped individuals. Two additonal classrooms, consisting of students of a second 11th-grade social studies teacher, participated as control groups. All students in the 4 treatment groups attended a minimum of 7 (out of 10) informational sessions.

The study was conducted in a senior high school located in an upper-middle-class suburban area of a large midwestern city. The target school served a variety of handicapped students, including mildly learning disabled and autistic and autistic-like, in addition to nonhandicapped pupils.

\section{Procedures}

The structured informational curricula were presented over a period of 10 weeks (one informational session per week). The 4 classrooms constituting the treatment groups were randomly assigned to either a categorical or a noncategorical curriculum. Two non-school staff researchers were randomly assigned to present both curricula; that is, each presented the categorical curriculum to one class and the noncategorical curriculum to a second class. The presenters were equally familiar with both the categorical and the noncategorical curriculum.

The informational activities consisted of the senior high curricula developed by the Severely Handicapped Integration Project, Department of Special Education, University of Kansas (Clark, Fiedler, Cozad, Novak, Sasso, \& Simpson, 1983).
(Additional information about the curriculum may be obtained from the second author.) Each curriculum (categorical and noncategorical) consisted of 10 50-minute lesson plans centered around a variety of instructional media and techniques such as films, filmstrips, records, simulations, large- and small-group discussions, handout activities, and individual writing assignments.

Categorical curriculum. The categorical curriculum was organized according to major categories of exceptionality. The 10 sessions included (a) an overview; (b) mental handicaps; (c) learning disabilities; (d) visual impairments; (e) hearing impairments; (f) physical disabilities; (g) health impairments; (h) emotional/behavior disorders; (i) personal acceptance; and (j) a review. Typically, informational sessions on a particular disability consisted of a discussion of standard definitions, common characteristics, possible causes, and simulations of the limitations imposed by the disability. Information was structured around the notion, "today we are going to learn about people who are mentally retarded, emotionally disturbed," etc.

Noncategorical curriculum. The noncategorical curriculum was developed to alleviate the potentially adverse effects of the traditional categorical reliance on disability labels. The noncategorical approach maintains that labeling is fraught with potential abuse and misunderstanding because labels represent a simplistic description of a complex set of variables (human behavior). Accordingly, labels may convey vague or imprecise meaning and are interpreted in relation to a person's previous experience with individuals given the same label. The potential for misunderstanding is further evident when one considers that any categorical disability label encompasses a wide variety of human behavior (abilities and disabilities).

The noncategorical curriculum used in this study systematically emphasized the importance of language in referring to people. Instead of identifying and discussing persons as "mentally retarded," handicapped individuals were presented in functional terms - what they were capable of doing in particular situations. Handicapped people were considered as individuals with skills and weaknesses in self-care abilities, receptive and expressive language, learning capacity, mobility, self-direction, economic 
sufficiency, and capacity for independent living. The noncategorical curriculum was based on the notion that when a label is employed to refer to a handicapped individual it tends to embody all one needs or cares to know about the labeled individual. All too often the label is mistaken for the person-we lose sight of the whole person. Further, the curriculum reflected the assumption that it is more helpful to think of handicapping situations than handicapped people. Accordingly, it considered adaptations, support, and training measures needed to assist a disabled person in eliminating or diminishing his/her handicapping situation.

The noncategorical curriculum used in the study was composed of 10 sessions: (a) values-acceptance or rejection; (b) individual differences; (c) effects of labels; (d) disability versus handicap; (e) handicapping dependencies; (f) self-fulfilling prophecies of dependence; (g) principle of normalization; (h) short-term solutions; (i) advocacy and self-advocacy; and (j) beneficial results through increased acceptance and integration of disabled people.

\section{Attitude Measurement}

A modified randomized Solomon four-group design (Isaac \& Michael, 1982) was employed. Pretesting was conducted in three of the classrooms (categorical, noncategorical, control) prior to exposing the subjects to any curricular information. All six groups (experimental and control) were posttested at the conclusion of the 10 sessions. This experimental design was employed to control for possible confounding effects of pretesting.

The dependent variable in the study-nonhandicapped high school students' attitude toward handicapped individuals-was measured using the following two instruments. The Attitude Toward Handicapped Individuals Scale (ATHI) (Lazar, Gensley, \& Orpet, 1971) is a 30-item, Likert-type (scores for each statement range from -3 [strongly disagree] to +3 [strongly agree]) scale. It is a modification of the Attitude Toward Disabled Persons' Scale (ATDP), originally developed by Yuker, Block, and Young (1970). The range of scores on the ATHI is from 0 to 180 , with higher scores representing greater acceptance of handicapped persons. The ATDP was modified in an effort to avoid the term "disabled" which was felt to be too restrictive. Instead, the term "handicapped" was substi- tuted in the ATHI, as it was considered to be more general and more applicable to studies of all categories of exceptionality (Lazar, Orpet, \& Revie, 1972). The ATHI requires subjects to react to statements such as, "Handicapped individuals can have a normal social life," "Handicapped workers can be as successful as other workers," or "Most handicapped individuals tend to get discouraged easily."

The ATHI scale has been widely used (Lazar, Stodden, \& Sullivan, 1976; Reinhardtsen, 1980) and has demonstrated satisfactory reliability and validity as a measure of nonhandicapped individuals' attitudes (Genskow \& Maglione, 1965; Lazar, Stodden, \& Sullivan, 1976; Reinhardtsen, 1980; Shaw \& Wright, 1967; and Yuker, Block, \& Campbell, 1960).

The second instrument used to measure attitude was the St. Joseph Curriculum-Based Attitude Scale (STJCBAS) (Reinhardtsen, 1980). On this 25-item, Likert-type scale students respond to statements regarding their involvement and attitude toward handicapped individuals. Responses to each item are marked on a 6-point scale ranging from "very much like me" to "very much unlike me." Similar to the ATHI, higher scores indicate more positive attitudes toward handicapped persons. Representative statements in this scale include: "I would be embarrassed to be seen in public with a retarded individual," "I think handicapped children should go to regular schools and be in regular classes," and "I would not mind eating in a restaurant which has handicapped employees."

Test-retest reliability for the STJCBAS was established by Reinhardtsen (1980). A Pearson Product-Moment Correlation Coefficient of + $.747(N=165)$ was found. The correlation between the STJCBAS and the ATHI was +.640 $(N=165)$.

\section{RESULTS}

An analysis of variance (ANOVA) procedure (Keppel, 1982) was used to determine whether significant differences existed among the pretest scores of the three subject groups-categorical, noncategorical, and control. Results of a comparison of mean pretest scores for both the ATHI and the STJCBAS were nonsignificant $(p>.05)$ : ATHI - categorical $(\bar{X}=109.33)$, noncategorical $(\bar{X}=111.10)$, and control $(\bar{X}=$ 110.66); STJCBAS - categorical $(\bar{X}=109.40)$, 
noncategorical $(\bar{X}=102.6)$ and control $(\bar{X}=$ 112.4). Further, a $3 \times 2$ factorial analysis of variance with unequal sample sizes (Keppel, 1982) was employed to determine whether significant differences existed among the pretest scores of males and females in the three subject groups. The results of the ATHI analysis were nonsignificant $(p>.05)$ for the treatment, sex, and interaction comparisons. Interestingly, however, results of the STJCBAS analysis yielded a significant sex difference in pretest scores $(F=$ $7.2, d f=1,39, p<.05$ ), with females scoring significantly higher (indicating a more positive attitude toward the disabled) than males.

Pretest and posttest difference scores were also compared by means of an analysis of variance procedure. Results from the ATHI scale $(F=19.11, d f=2,42, p<.01)$ were significant. Post hoc multiple comparisons using the Scheffé technique indicated that structured informational presentations (categorical and noncategorical combined) yielded significant positive attitude change when compared to the control group $(F=9.69, d f=2,42, p<.05)$. Significant differences also favored the categorical over the control group $(F=16.59, d f=2,42, p<.01)$, and the categorical group over the noncategorical $(F=8.35, d f=2,42, p<.05)$. A similar analysis was conducted using STJCBAS preand posttest difference scores. Again, results were significant $(F=8.30, d f=2,42, p<.01)$. Furthermore, Scheffé test results indicated a significant increase in attitude scores for the two informational treatment (categorical and noncategorical) groups when compared to the control condition $(F=11.66, d f=2,42, p<$ .01 ) and the categorical group compared to the control $(F=16.56, d f=2,42, p<.01)$.

Pretest and posttest difference scores for both the ATHI and STJCBAS were examined for sex differences among the three subject groups using $3 \times 2$ factorial analysis of variance. The ATHI analysis resulted in a significnt main effect for the treatment condition $(F=6.07, \mathrm{df}$ $=2,39, p<.01$ ), but nonsignificant results for the sex and treatment $\times$ sex interaction conditions. The STJCBAS analysis revealed nonsignificant results among the sex, treatment, and treatment $\times$ sex interaction conditions.

All six groups' posttest scores were analyzed by grouping the two categorical groups, the two noncategorical classes, and the two control classrooms ( $N=30$ for each group). Table 1 summarizes the mean posttest scores of non- handicapped students' attitude by treatment group and sex, as measured by the ATHI and the STJCBAS. In order to determine if the differences were statistically significant, a $3 \times$ 2 factorial analysis of variance with unequal sample sizes was employed (Keppel, 1982).

The results of the ATHI analysis revealed significant main effects for the treatment condition $(F=5.66, d f=2,84, p<.01)$ and sex comparison $(F=7.3 \mathrm{df}=1,84, p<.05)$. The treatment $\times$ sex interaction was found to be nonsignificant $(p>.05)$. Scheffé test comparisons revealed a significant difference between the categorical and control groups $(F=9.13$, $d f=2,87, p<.01$ ).

The analysis of variance assessment of STJCBAS mean posttest scores were in accordance with the ATHI findings. Specifically, significant main effects for the treatment condition $(F=4.13, d f=2,84, p<.05)$ and sex comparison $(F=9.05, d f=1,84, p<.01)$ were noted. However, no significant treatment $\times$ sex interaction effect was found. In spite of the significant main effects, results of the Scheffé test comparisons were nonsignificant.

\section{DISCUSSION}

The results of the present study support the efficacy of informational presentations in positively modifying nonhandicapped students' attitudes toward handicapped individuals. These findings are consistent with those of other studies (McHale \& Simeonsson, 1980; Newman \& Simpson, 1983; Reinhardtsen, 1980; Sasso, 1983; Voeltz, 1980). Consequently, they should prove encouraging to regular educators as they work with special educators in an effort to enhance integration of handicapped students within public school buildings and classrooms.

\section{Categorical Curriculum Superiority}

The most salient finding of this study was that the categorical curriculum consistently (across both measurement instruments) resulted in more positive attitude scores than the noncategorical curriculuri. Accordingly, it may be concluded, at least tentatively, that the categorical approach is effective in disseminating information on specific disability traits and characteristics while having a positive effect on nonhandicapped students' attitudes toward individuals labeled as handicapped. 
Several explanations exist for the superiority of the categorical curriculum. First, the noncategorical strategy of subjecting nonhandicapped students' personal beliefs and values to scrutiny may have caused discomfort. That is, the noncategorical curriculum approach of noting the manner in which commonly held values (e.g., physical attractiveness, athletic ability, intelligence, material wealth) often result in a devaluation of handicapped individuals, who rarely manifest such values or personal attributes, may have generated anxiety and hence inhibited empathic understanding.

Similarly, the noncategorical approach of exposing regular class students to the adverse life conditions of many handicapped people residing in large, overcrowded, and understaffed institutions may have generated discomfort which reduced attitude change. Graphic descriptions of institutional life were provided under the assumption that such exposure would lead regular class students to ponder and question the historical mistreatment of handicapped persons and cause them to examine their personal beliefs. However, students exposed to the noncategorical curriculum may have experienced greater uneasiness than their counterparts who received categorical treatment. This discomfort may have acted as a restraining force in the formation of positive attitudes toward the handicapped.

A related explanation for the findings was that the categorical approach simply met the needs of the regular class students better than did the noncategorical curriculum. That is, learning about the characteristics and other distinctive features of exceptional persons may have filled a cognitive void while at the same time replacing misinformation and stereotypes with facts. Additionally, such learning did not require personal commitment or involvement. The noncategorical strategy, on the other hand, attempted to cultivate the philosophy that nonhandicapped people must assume some personal responsibility for the life conditions and opportunities accorded handicapped persons. Some students exposed to this philosophy may have experienced discomfort which reduced their level of acceptance.

\section{Attitudes of Females and Males}

An additional finding was that females held significantly more favorable attitudes toward
TABLE 1

Mean Posttest Scores of Nonhandicapped Students' Attitudes Toward Handicapped Individuals on Two Scales

\begin{tabular}{|c|c|c|c|c|}
\hline \multirow[b]{2}{*}{$\begin{array}{l}\text { Treatment } \\
\text { Group }\end{array}$} & \multicolumn{2}{|c|}{$\mathrm{ATH}^{a}$} & \multicolumn{2}{|c|}{ STJCBAS $^{b}$} \\
\hline & Means & $\begin{array}{l}\text { Standard } \\
\text { Deviation }\end{array}$ & Means & $\begin{array}{l}\text { Standard } \\
\text { Deviation }\end{array}$ \\
\hline \multicolumn{5}{|c|}{ Categorical Curriculum } \\
\hline $\begin{array}{l}\text { Males } \\
(N=15)\end{array}$ & 121.93 & 18.88 & 109.73 & 14.09 \\
\hline $\begin{array}{l}\text { Females } \\
(N=15)\end{array}$ & 132.46 & 18.18 & 120.13 & 10.82 \\
\hline \multicolumn{5}{|c|}{ Noncategorical Curriculum } \\
\hline $\begin{array}{l}\text { Males } \\
(N=13)\end{array}$ & 103.08 & 15.11 & 97.15 & 20.37 \\
\hline $\begin{array}{l}\text { Females } \\
N=17)\end{array}$ & 124.47 & 20.35 & 111.24 & 13.55 \\
\hline \multicolumn{5}{|c|}{ Control } \\
\hline $\begin{array}{l}\text { Males } \\
(N=15)\end{array}$ & 109.08 & 18.64 & 105.33 & 13.45 \\
\hline $\begin{array}{l}\text { Females } \\
(N=15)\end{array}$ & 112.06 & 23.21 & 109.20 & 13.40 \\
\hline
\end{tabular}

${ }^{a}$ ATHI is the Attitude Toward Handicapped Individuals Scale. 'bTJCBAS is the St. Joseph CurriculumBased Attitude Scale.

handicapped persons than their male counterparts. This finding, which is consistent with results of previous research (Greenbaum \& Wang, 1965; Newman \& Simpson, 1983; Simpson, Parrish, \& Cook, 1976), should be taken into consideration as integration efforts proceed in the schools. That is, if females' attitudes are naturally more positive and more easily changed in a positive direction, female students would be the most likely candidates to serve initially as peer tutors or role models for handicapped students. Positive attitudes change, with resultant increased contact between handicapped students and preselected female students, could have positive spin-off effects, and ultimately, encourage the participation of more nonhandicapped students, including males.

\section{Measurement Issues}

The issue of whether pencil-paper scales accurately measure attitude is germane to the present 
study. That is, in spite of the use of reliable and valid procedures and instruments it must be empirically determined whether the findings generalize to other populations and whether stated attitudes would have translated into overt behavior. Hence, attitude scale data must be interpreted with some skepticism. Yet, in spite of this inherent weakness the results of the present study must be accepted until different results based on more functional measures are presented.

\section{Educational Implications}

The educational implications of the present data are obvious. The ever increasing presence of identified exceptional children and adolescents in public schools necessitates that nonhandicapped persons in these settings, including regular class students, be made aware of the needs, characteristics, and issues facing handicapped individuals. Curricular interventions can facilitate this process.

Dissemination of relevant information and arrangement of appropriate experiences leading to this goal is not exclusively a special education function, however. Both regular and special educators must share "ownership" of the problem of how to make handicapped students more accepted and viable parts of their school and, eventually, community. The results of the present study add to existing evidence regarding the efficacy of curricular presentations in positively modifying nonhandicapped students' attitudes toward the handicapped. Such results are noteworthy because regular educators can employ these procedures without extensive training or experience with handicapped students. Ultimately, increased use of such curricular procedures will likely foster a more effective partnership between regular and special educators. While the precise curricula, including categorical versus noncategorical and other particulars, have yet to be defined, influencing the attitude of regular class students toward exceptional persons must be made a regular part of educational programming.

\section{REFERENCES}

Ayer, M. J. (1970). Employability of handicapped individuals in the teaching professions: Considerations for rehabilitation counseling. Rehabilitation Counseling Bulletin, 13, 364-373.

Barker, R. G., Wright, B. A., Meyerson, L., \& Gonich,
M. R. (1953). Adjustment to physical handicap and illness. New York: Social Sciences Research Council.

Barnes, E., Berrigan, C., \& Biklen, D. (1978). What's the difference: Teaching positive attitudes toward people with disabilities. Syracuse, NY: Human Policy Press.

Biklen, D., \& Sokoloff, M. (1978). What to do when your wheelchair gets a flat tire? New York: Scholastic Magazine, Inc.

Bogdan, R., \& Taylor, S. J. (1982). Inside out. Toronto: University of Toronto Press.

Bookbinder, S. R. (1978). Meeting street school curriculum. Boston: Exceptional Parent Press.

Clark, P. A., Fiedler, C. R., Cozad, S. K., Novak, C. G., Sasso, G. M., \& Simpson, R. L. (1983). Attitude change curricula: Senior high level. Lawrence, KS: University of Kansas Special Education.

Cohen, S. (1977). Accepting individual differences. Niles, IL: Developmental Learning Materials.

Evans, J. H. (1976). Changing attitudes toward disabled persons: An experimental study. Rehabilitation Counseling Bulletin, 19, 572-579.

Fiedler, L. (1978). Freaks, myths and images of the secret self. New York: Simon and Schuster.

Foster, G. G., Ysseldyke, J. E., \& Reese, J. H. (1975). I wouldn't have seen it if I hadn't believed it. Exceptional Children, 41, 469-473.

Genskow, J. W., \& Maglione, F. D. (1975). Familiarity, dogmatism, and reported student attitudes toward the disabled. The Journal of Social Psychology, $67,329-341$.

Greenbaum, J. J., \& Wang, D. D. (1965). A semanticdifferential study of the concepts of mental retardation. Journal of General Psychology, 73, 257-272.

Guskin, S. L. (1963). Measuring the strength of the stereotype of the mental defective. American Journal of Mental Deficiency, 67(4), 569-575.

Isaac, S., \& Michael, W. B. (1982). Handbook in research and evaluation. San Diego: Edits Publishers.

Keppel, G. (1982). Design and analysis: A researcher's handbook. Englewood Cliffs, NJ: Prentice-Hall, Inc.

Larsen, S. C. (1975). The influence of teacher expectations on the school performance of exceptional children. Focus on Exceptional Children, 6, 1-14.

Lazar, A. L., Gensley, J. T., \& Orpet, R. E. (1971). Changing attitudes of young mentally gifted children toward the handicapped. Exceptional Children, 37(8), 600-602.

Lazar, A. L., Orpet, R. E., \& Revie, V. A. (1972). Attitudes of young gifted boys and girls toward handicapped individuals. Exceptional Children, $38,489-490$.

Lazar, A. L., Stodden, R. L., \& Sullivan, N. V. (1976). A comparison of attitudes held by male and female future school administrators toward instructional goals, personal adjustment, and the 
handicapped. Rehabilitation Literature, 37(7), 198201.

Martin, E. W. (1974). Some thoughts on mainstreaming. Exceptional Children, 41, 150-153.

McHale, S. M., \& Simeonsson, R. J. (1980). Effects of interaction on handicapped childrens' attitudes toward autistic children. American Journal of Mental Deficiency, 85, 18-24.

MacMillan, D. L., Jones, R. L., \& Aloia, G. G. (1974). The mentally retarded label: A theoretical analysis and review of research. American Journal of Mental Deficiency, 79, 241-261.

Newman, R. K., \& Simpson, R. L. (1983). Modifying the least restrictive environment to facilitate the integration of severely emotionally disturbed children and youth. Behavioral Disorders, 4(2), 103112.

Nirje, B. (1969). The normalization principle and its human management implications. In R. Kugel \& W. Wolfensberger (Eds.), Changing patterns in residential services for the mentally retarded. Washington, DC: President's Committee on Mental Retardation.

Novak, A., \& Heal, L. (1980). Integration of developmentally disabled individuals into the community. Baltimore: Paul H. Brooks Publishing Co.

Panda, I. C., \& Bartel, N. C. (1972). Teacher perception of exceptional children. Journal of Special Education, 6, 261-265.

Ramsey, P. (1978). Ethics at the edge of life. New Haven, CT: Yale University Press.

Reinhardtsen, J. (1980). The effects of a structured informational program on the attitudes of regular high school students toward the handicapped. Unpublished doctoral dissertation, University of Kansas, Lawrence.

Sasso, G. M. (1983). The effects of multiple procedures on the behavior and attitudes of nonhandicapped students toward their severely emotionally disturbed peers. Unpublished doctoral dissertation, University of Kansas, Lawrence.

Shaw, M. E., \& Wright, J. M. (1967). Scales for the measurement of attitudes. New York: McGrawHill.

Simpson, R. L. (1980). Modifying the attitudes of regular class students toward the handicapped. Focus on Exceptional Children, 13, 1-11.

Simpson, R. L., Parrish, N. B., \& Cook, J. J. (1976). Modification of attitudes of regular class children towards the handicapped for the purpose of achieving integration. Contemporary Educational Psychology, 2, 46-51.

Stainback, W., Stainback, S., Raschke, D., \& Anderson, R. J. (1981). Three methods for encouraging interactions between severely retarded and nonhandicapped students. Education and Training of the Mentally Retarded, 16(3), 188-192.

Voeltz, L. (1980). Children's attitudes toward handicapped peers. American Journal of Mental Defi- ciency, 84, 455-464.

Voeltz, L. (1982). Effects of structured interactions with severely handicapped peers on children's attitudes. American Journal of Mental Deficiency, 86, 380-390.

Wilson, W. (1970). Social psychology and mental retardation. In N. R. Ellis (Ed.), International review of research in mental retardation, Vol. 4 . New York: Academic Press.

Wolfensberger, W. (1972). The principle of normalization in human services. Toronto: National Institute on Mental Retardation.

Yuker, H. E., Block, J. R., \& Campbell, W. J. (1960). A scale to measure attitudes toward disabled persons: Study No. 5. Albertson, NY: Human Resources Foundation.

Yuker, H. E., Block, J. R., \& Young, J. H. (1970). The measurement of attitudes toward disabled persons. Albertson, NY: Human Resource Center.

Manuscript received May 1984; final revision accepted February 1985.

\section{Manuscripts Invited: Early Childhood Mathematics}

The Editorial Panel of the Arithmetic Teacher invites authors to submit manuscripts for a focus issue on mathematics learning and instruction at the early childhood level (ages 3-8). The topics below are suggested for prospective authors. Five copies of a completed manuscript should be sent for review to the Arithmetic Teacher, 1906 Association Drive, Reston, VA 22091, by 1 February, 1987.

- Psychological bases for learning.

- Conceptual development.

- Meaningful skill development.

- Content areas.

- Use of technology.

- Assessment of skills and understanding.

- Teacher background and preparation.

- Parental involvement.

- Classroom instruction, management, and organization.

- Interdisciplinary approaches.

- Promising practices, future directions. 